RESEARCH ARTICLE

\title{
Evaluation of Ethyl Acetate Extract of Some Botanicals against Rice Weevil Sitophilus oryzae L. (Coleoptera: Curculionidae) in Stored Maize
}

\author{
Anandhabhairavi $\mathbf{N}^{1}$, Shanthi $\mathbf{M}^{1 *}$, Chinniah $\mathbf{C}^{1}$, Geetha $\mathbf{R}^{2}$ and Vellaikumar $\mathbf{S}^{3}$ \\ ${ }^{1}$ Department of Agricultural Entomology, Agricultural College and Research Institute, \\ Tamil Nadu Agricultural University, Madurai- 625104. \\ ${ }^{2}$ Department of Seed Science and Technology, Agricultural College and Research Institute , \\ Tamil Nadu Agricultural University, Madurai- 625104. \\ ${ }^{3}$ Department of Biotechnology, Agricultural College and Research Institute, Tamil Nadu Agricultural University, Madurai- 625104.
}

\begin{abstract}
In the present study, botanicals (11 nos.) were extracted using ethyl acetate solvent (mid-polar) and evaluated for their fumigant toxicity and repellent activity at $5 \%$ concentration against rice weevil, Sitophilus oryzae L. in comparison with Acorus calamus. The results revealed that all the botanicals were effective against Sitophilus oryzae compared to untreated control. Mentha spicata $5 \%$ ethyl acetate extract exhibited $83.33 \%$ fumigant toxicity after 72 hours of treatment with maximum repellency rate of $76.11 \%$. Ocimum sanctum displayed $80.00 \%$ fumigant toxicity with the repellency rate of $76.11 \%$ and grouped under Class IV. Vitex negundo 5\% treatment caused $83.33 \%$ fumigant toxicity, and it was statistically on par with the M. spicata and the repellency rate was 72.78 against S. oryzae. Curcuma longa caused effective repellency rate of $75.56 \%$ and was grouped under Class IV. Hence, it is concluded that $5 \%$ ethyl acetate extract of $M$. spicata, $V$. negundo and O.sanctum were toxic against S. oryzae in stored maize.
\end{abstract}

Keywords: Sitophilus oryzae; Ethyl acetate extracts; Botanicals; Fumigant toxicity; Repellency

\section{INTRODUCTION}

Plant metabolites can be classified into two main classes, primary and secondary metabolites. Primary metabolites are essential for the continued existence of the organism by which they are produced, but secondary metabolites mainly affect other organisms. Secondary metabolites include terpenoids, alkaloids, glycoside, phenols, tannins etc., which play a significant role in plant defense and cause behavioral and physiological effects on insects. Among them, terpenoids are the largest group of naturally occurring compounds, which are further subdivided into various classes; out of them, monoterpenes and sesquiterpenes are the main components (Batish et al., 2008). Plant vital compounds exhibit a wide range of biological activity against crop pests and may act as contact insecticides, oviposition deterrents, antifeedants, repellents, fumigants or they can influence the behavior and growth rate of insect pests.

Regarding S. oryzae, both grub and adults of rice weevils cause damage to the grain. They are internal feeders, and the entire development cycle occurs within the kernel. Adults can fly and easily distribute themselves throughout a storage facility because of their flight ability. They may also infest grain while the crop is still standing in the field, especially if the harvest is delayed and mild temperatures. Because of this fact, it is essential to inspect incoming loads for this pest when the loads are coming directly from the field. One pair of S. oryzae can reproduce about one million of its species within a period of 3 months under favorable conditions (Thomas et al., 2002). The prevention of losses in stored products due to insects is of paramount importance.

Thus, unless control measures are taken, heavy infestations may take place. Additionally, the kernel damage caused by $\mathrm{S}$. oryzae grub enables other external feeders to infest the damaged grain; hence the damage increases rapidly. Further, it is high time to protect the grains in an ecofriendly way. It is the need of the hour in the present trend of livelihood to keep pace with our future generation to tackle storage problems. Keeping this in view, this study aims to focus on the utilization of plant metabolits as a bioinsecticide. 


\section{MATERIAL AND METHODS}

The experiment was conducted at Natural Pesticide Laboratory. Department of Agricultural Entomology, Agricultural College and Research Institute, Madurai during 2019.

\section{Test insects}

The insect culture was maintained in laboratory at room temperature $30 \pm 2{ }^{\circ} \mathrm{C}$ and $70 \pm 5 \%$ relative humidity. They were reared in the laboratory to obtain the first generation (F1) for use in bioassays. The maize seeds were dried in hot air oven at $40{ }^{\circ} \mathrm{C}$ for 48 hours to eliminate possible insect infestation from the field. About 200 numbers of adult weevils (mixed sex) were released in plastic jars (1lit capacity) filled with clean, undamaged and sterilized 500 gms of whole maize seeds and covered with perforated plastic lids to allow gas exchange.

\section{Procurement of raw materials for extraction of natural insecticides}

Totally 11 botanicals were selected for evaluation in comparison with Acorus calamus as treated check, acetone as positive control and untreated check as a negative control. The plant extracts were obtained from the healthy, mature and succulent leaves/rhizomes/flowers of the selected plants. The leaves of Eucalyptus globulus, Lantana camara, Murraya koenigii, Ricinis communis and Vitex negundo were collected in and around the campus, Tagetes erecta leaves and flowers were collected from farmer's field, leaves of Citrus aurantium were collected from Thadiyankudisai, the rhizome of Curcuma longa, leaves of Ocimum sanctum and Mentha spicata were purchased from the local market. The collected samples were dried under shade at room temperature of $29^{\circ} \mathrm{C}$ to $30{ }^{\circ} \mathrm{C}$ for 10 days and ground into fine powder using an electric grinder and sieved through a mesh sieve $(0.1 \mathrm{~mm}$ pore size) to get uniform particle size. The leaf powders were kept separately in plastic containers in a dark place until used for extraction.

\section{Preparation of Ethyl Acetate extracts}

The $100 \mathrm{~g}$ of dried powder was separately macerated in $1000 \mathrm{~mL}$ ethyl acetate (mid-polar solvent). Then the mixture was stirred for 2 hours in a magnetic stirrer at (2000 rpm) and left to stand for 24 hours. After 24 hours, the contents were carefully filtered through Whatman No.1 filter paper. The extract was concentrated using a rotary evaporator at $40{ }^{\circ} \mathrm{C}$ under reduced pressure to get the crude ethyl acetate extract. The residue obtained as weighed and stored in glass vials and maintained in a refrigerator $\left(4^{\circ} \mathrm{C}\right)$ until bioassays.

\section{Fumigant toxicity}

Five percent concentration of ethyl acetate extracts was prepared earlier by diluting with acetone, and filter paper discs of $1.5 \mathrm{~cm}$ diameter were impregnated with different treatments ( $2 \mu \mathrm{L} /$ $\mathrm{cm}^{3}$ ) separately. The filter paper discs were allowed to evaporate the solvent for $2 \mathrm{~min}$. After that, the filter paper discs were attached to the inner surface of the screw cap of glass vials (25 mLcapacity) separately. Ten numbers of weevils were released into the vials with 20 maize seeds separately. The neck of the vials was blocked with nylon cloth to avoid direct contact of insects with paper disc. The cap of each vial was screwed tightly and kept at 28 $\pm 2{ }^{\circ} \mathrm{C}$ temperature. Mortality was observed after 24, 48 and 72 hours of exposure. Each treatment and control was replicated three times (Huang et al., 2000; Pandey et al., 2011; Jayakumar et al., 2017). Mortality was considered when the weevil did not respond to gentle pressure using a fingertip. Percentage insect mortality was calculated using the corrected formula of Abbott (1925).

\section{Repellency test}

The repellency effect of ethyl acetate extract of botanicals was tested by applying $1 \mathrm{~mL}$ of $5 \%$ concentration uniformly on one half of the filter paper and acetone was applied on another halves, which was used as an untreated check. A $9 \mathrm{~cm}$ diameter of filter paperwas cut into two halves and used for the experiment. Both the treated and untreated half circles were allowed to dry to evaporate the solvent. The entire disc of the treated and untreated half circles was remade by attaching with adhesive tape from the lower side and placed on the Petri dishes. Ten newly emerged adult weevils were released in the middle of the two halves and were covered with the lid. The inner side of the lid was coated with vaseline to prevent the weevil staying on the lid. The repellency treatment was replicated three times. S. oryzae present on the treated and untreated halves was recorded at every one-hour interval from one to twenty-four hours. The per cent repellent activity of plant extracts was investigated by the method described by Talukdar and Howse (1993, 1994). Data from all treatments was converted to express percentage repulsion (PR) by the following formula (Valsala and Gokuldas, 2015).

$$
\text { Per cent repellency }(\%)=\frac{\text { NC-NT } \times 100}{\mathrm{NC}+\mathrm{NT}}
$$

Where, half

$\mathrm{NC}=$ Percentage of weevils present in the control

$$
\text { NT = Percentage of weevils present in the treated }
$$
half

Based on per cent repellency, the concentrations were grouped into different classes. 
Class Repellency rate

\begin{tabular}{lc}
\hline Repellency Rate (\%) & Class \\
\hline $0.01-<0.1$ & 0 \\
$0.1-20$ & I \\
$20.1-40$ & II \\
$40.1-60$ & III \\
$60.1-80$ & IV \\
$80.1-100$ & V \\
\hline
\end{tabular}

\section{Statistical analysis}

The experiment was laid at Completely Randomized Block Design (CRD). The per cent mortality and repellency were determined, transformed to arcsine values and statistically analyzed by using SPSS software (version 16) to carry out analysis of variance (ANOVA). Grouping of data was done by using Duncan's Multiple Range Test (DMRT) (Gomez and Gomez, 1984).

\section{RESULTS AND DISCUSSION}

The results revealed that all the botanicals exhibited toxicity against $S$. oryzae compared to untreated check and acetone control, while the treated check Acorus calamus was efficient than the treatments.

\section{Phytochemical recovery}

The phytochemical recovery using ethyl acetate (Midpolar solvent) from the selected botanicals was found to range from 2.50 to 43.45 per cent (Table 1 ). Among the tested botanicals, the leaves of Lantana camara yielded the maximum of 43.45 per cent followed by 10.20 per cent in $C$. longa rhizome and 9.30 per cent in $R$. communis leaves.

\section{Fumigant toxicity}

The results on the fumigant toxicity of ethyl acetate extracts against $\mathrm{S}$. oryzae is presented in
Figure 1. The treated check A.calamus performed better and recorded the highest mortality (96.67\%) of S. oryzae at $1 \%$ concentration 72 hours after treatment. Among the test botanicals, 5\% of M.spicata and V. negundo $5 \%$ extracts showed more fumigant toxicity (83.33\%) 15 days after treatment, followed by 0 . sanctum 5\% (80.00\%) 15 days after treatment.

The current results were corroborating with the findings of Ainane et al. (2019), who reported that the $2 \mu \mathrm{L} / \mathrm{cm}^{3}$ concentration of $M$. spicata essential oils caused $100 \%$ mortality, M.piperita caused 96.66\% and M.pulegium caused $86.66 \%$ mortality against S.granarius and for S.oryzae the M.spicata caused $100 \%$ mortality, M.pulegium caused $96.66 \%$ mortality and M.piperita caused $90.00 \%$ mortality and for S.zeamais, the M.spicata and M.piperita caused $100 \%$ mortality and for M.pulegium showed $86.66 \%$ mortality after 24 hours of exposure.

Ainane et al. (2019) reported that the $1.5 \mu \mathrm{L} /$ $\mathrm{cm}^{3}$ concentration of $M$. spicata oils showed 83.33\% mortality M.piperita showed $76.66 \%$, $M$. pulegium $70 \%$ mortality against S. granarius and for the S.oryzae M. spicata oil caused 53.33\%, M.piperita $56.66 \%$ and M. pulegium $56.66 \%$ mortality after 24 hours of exposure. The average $\left(1.5 \mu \mathrm{L} / \mathrm{cm}^{3}\right)$ concentration of M.spicata, M.piperita and M.pulegium oils caused $23.33 \%, 50.00 \%$ and $50 \%$ mortality against S. zeamais. Demeter et al. (2021) reported that $5 \%$ of M.arvensis essential oils showed $100 \%$ mortality against S.granarius. and 0 . sanctum $(99.00 \%)$ mortality against S.granarius at 24 hours after treatment and O.basilicum essential oils showed $97.70 \%$ mortality at 24 hours after treatment against S.granarius. El-Salam (2010) observed that $100 \%$ mortality of $C$.chinensis after 3 days exposure to 0 . basilicum EO at $1.0 \mathrm{~mL} / 38.5 \mathrm{~mL}$ air.

Table 1. Recovery of bioactive compounds from botanicals using ethyl acetate compounds

\begin{tabular}{|c|c|c|c|c|c|}
\hline S. No. & Common Name & Scientific Name & Family & Plant Parts & Extraction recovery \% \\
\hline 1 & Sour orange & Citrus aurantium L. & Rutaceae & Leaves & 2.62 \\
\hline 2 & Turmeric & Curcuma longa L. & Zingiberaceae & Rhizome & 10.20 \\
\hline 3 & Tasmanian blue gum & Eucalyptus globulus Labill & Myrtaceae & Leaves & 7.80 \\
\hline 4 & Big sage & Lantana camera L. & Verbenaceae & Leaves & 43.45 \\
\hline 5 & Spear mint & Mentha spicata L. & Lamiaceae & Leaves & 4.15 \\
\hline 6 & Curry tree & Murraya koenigii Sprengel & Rutaceae & Leaves & 4.75 \\
\hline 7 & Basil & Ocimum sanctum L. & Lamiaceae & Leaves & 5.75 \\
\hline 8 & Castor & Ricinis communis L. & Euphorbiaceae & Leaves & 9.30 \\
\hline 9 & Marigold & Tagetes erecta L. & Asteraceae & Leaves & 2.95 \\
\hline 10 & Marigold & Tagetes erecta L. & Asteraceae & Flower & 2.51 \\
\hline 11 & Indian privet & Vitex negundo L. & Lamiaceae & Leaves & 2.50 \\
\hline
\end{tabular}


Saad et al. (2018) estimated that the $\mathrm{LC}_{50}$ value of eugenol against S.oryzae was $>100 \mu \mathrm{L} / \mathrm{L}$ air at 24-hour exposure. Shaaya et al. (1997) showed that the $\mathrm{LC}_{50}$ values of O.basilicum essential oil against
S.oryzae was $>15 \mu \mathrm{L} / \mathrm{L}$ air. Bhavya et al. (2018) who reported that the $479 \mu \mathrm{L} / \mathrm{L}$ air of O.tenuiflorum essential oil was required for $50 \%$ mortality for 24 hours after treatment.

Table 2. Repellency of ethyl acetate extract of different plant materials against adults of S. oryzae

\begin{tabular}{|c|c|c|c|c|c|c|c|c|}
\hline \multirow{2}{*}{ Treatments } & \multicolumn{6}{|c|}{ Repellency (\%) } & \multirow{2}{*}{$\begin{array}{c}\text { Mean } \\
\text { - Repellency } \\
(\%)\end{array}$} & \multirow{2}{*}{$\begin{array}{c}\text { Class } \\
\text { Repellency }\end{array}$} \\
\hline & $1 \mathrm{hr}$ & $2 \mathrm{hr}$ & $3 \mathrm{hr}$ & $4 \mathrm{hr}$ & $6 \mathrm{hr}$ & $24 \mathrm{hr}$ & & \\
\hline T1- & $56.67 \pm 0.00$ & $63.33 \pm 5.77$ & $70.00 \pm 0.00$ & $66.67 \pm 5.77$ & $63.33 \pm 5.77$ & $73.33 \pm 5.77$ & 65.56 & \\
\hline C.aurantium & $(50.76)^{\text {bcde }}$ & $(52.77)^{\text {def }}$ & $(56.79)^{\mathrm{bcd}}$ & $(54.78)^{\mathrm{cd}}$ & $(52.77)^{c}$ & $(59.00)^{b}$ & $(54.48)^{\mathrm{de}}$ & IV \\
\hline T2- & $63.33 \pm 5.77$ & $73.33 \pm 5.77$ & $76.67 \pm 5.77$ & $76.67 \pm 5.77$ & $83.33 \pm 5.77$ & $80.00 \pm 0.00$ & 75.56 & \\
\hline C.longa & $(54.78)^{\mathrm{bc}}$ & $(59.00)^{\mathrm{bc}}$ & $(61.21)^{b c}$ & $(61.21)^{b c}$ & $(66.14)^{b}$ & $(63.43)^{b}$ & $(60.96)^{b}$ & IV \\
\hline T3- & $56.67 \pm 5.77$ & $53.33 \pm 5.77$ & $60.00 \pm 10.00$ & $60.00 \pm 0.00$ & $70.00 \pm 0.00$ & $73.33 \pm 5.77$ & 62.22 & \\
\hline E. globulus & $(46.92)^{\mathrm{de}}$ & $(46.92)^{f}$ & $(50.85)^{d}$ & $(50.76)^{d}$ & $(56.79)^{\mathrm{bc}}$ & $(59.00)^{b}$ & $(51.87)^{\mathrm{e}}$ & IV \\
\hline T4- & $56.67 \pm 5.77$ & $66.67 \pm 5.77$ & $70.00 \pm 0.00$ & $76.67 \pm 5.77$ & $76.67 \pm 5.77$ & $73.33 \pm 5.77$ & 70.00 & \\
\hline L. camara & $(52.77)^{\mathrm{bcd}}$ & $(54.78)^{\text {cde }}$ & $(56.79)^{\mathrm{bcd}}$ & $(61.21)^{\mathrm{bc}}$ & $(61.21)^{b c}$ & $(59.00)^{b}$ & $(57.63)^{\mathrm{cd}}$ & \\
\hline T5- & $63.33 \pm 10.00$ & $73.33 \pm 5.77$ & $80.00 \pm 0.00$ & $80.00 \pm 10.00$ & $83.33 \pm 5.77$ & $76.67 \pm 5.77$ & 76.11 & \\
\hline M. spicata & $(56.99)^{b}$ & $(59.00)^{\mathrm{bc}}$ & $(63.43)^{\mathrm{ab}}$ & $(63.92)^{\mathrm{ab}}$ & $(66.14)^{b}$ & $(61.21)^{b}$ & $(61.79)^{\mathrm{b}}$ & 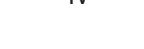 \\
\hline T6- & $56.67 \pm 0.00$ & $56.67 \pm 5.77$ & $60.00 \pm 10.00$ & $66.67 \pm 5.77$ & $63.33 \pm 5.77$ & $73.33 \pm 5.77$ & 62.78 & \\
\hline M. koenigii & $(45.00)^{\mathrm{e}}$ & $(48.84)^{\mathrm{ef}}$ & $(50.85)^{d}$ & $(54.78)^{\mathrm{cd}}$ & $(52.77)^{c}$ & $(59.00)^{b}$ & $(51.87)^{\mathrm{e}}$ & 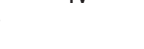 \\
\hline T7- & $60.00 \pm 5.77$ & $76.67 \pm 5.77$ & $76.67 \pm 5.77$ & $76.67 \pm 5.77$ & $83.33 \pm 5.77$ & $83.33 \pm 5.77$ & 76.11 & \\
\hline O. sanctum & $(54.78)^{\mathrm{bc}}$ & $(61.21)^{\mathrm{ab}}$ & $(61.21)^{\mathrm{bc}}$ & $(61.21)^{\mathrm{bc}}$ & $(66.14)^{b}$ & $(66.14)^{\mathrm{b}}$ & $(61.79)^{b}$ & \\
\hline T8- & $63.33 \pm 0.00$ & $60.00 \pm 0.00$ & $70.00 \pm 0.00$ & $70.00 \pm 0.00$ & $63.33 \pm 5.77$ & $73.33 \pm 5.77$ & 66.67 & \\
\hline R.communis & $(50.76)^{\text {bcde }}$ & $(50.76)^{\text {def }}$ & $(56.79)^{\mathrm{bcd}}$ & $(56.79)^{\mathrm{bcd}}$ & $(52.77)^{c}$ & $(59.00)^{b}$ & $(54.48)^{\text {de }}$ & \\
\hline T9- & $56.67 \pm 11.55$ & $60.00 \pm 0.00$ & $66.67 \pm 5.77$ & $66.67 \pm 5.77$ & $73.33 \pm 5.77$ & $76.67 \pm 5.77$ & 66.67 & \\
\hline T. erecta & $(48.93)^{\text {cde }}$ & $(50.76)^{\text {def }}$ & $(54.78)^{c d}$ & $(54.78)^{c d}$ & $(59.00)^{\mathrm{bc}}$ & $(61.21)^{b}$ & $(54.91)^{\mathrm{de}}$ & IV \\
\hline T10- & $60.00 \pm 5.77$ & $60.00 \pm 10.00$ & $60.00 \pm 10.00$ & $60.00 \pm 0.00$ & $63.33 \pm 11.55$ & $73.33 \pm 5.77$ & 62.78 & \\
\hline T. erecta & $(46.92)^{\mathrm{de}}$ & $(50.85)^{\text {def }}$ & $(50.85)^{d}$ & $(50.76)^{d}$ & $(52.86)^{\mathrm{bc}}$ & $(59.00)^{b}$ & $(51.87)^{\mathrm{e}}$ & IV \\
\hline T11 - & $60.00 \pm 0.00$ & $70.00 \pm 0.00$ & $76.67 \pm 5.77$ & $73.33 \pm 5.77$ & $76.67 \pm 5.77$ & $80.00 \pm 0.00$ & 72.78 & \\
\hline $\begin{array}{l}\text { V. negundo } \\
\text { T12- }\end{array}$ & $(50.76)^{\text {bcde }}$ & $(59.79)^{\mathrm{bcd}}$ & $(61.21)^{\mathrm{bc}}$ & $(59.00)^{\mathrm{bc}}$ & $(61.21)^{\mathrm{bc}}$ & $(63.43)^{b}$ & $(58.74)^{\mathrm{bc}}$ & \\
\hline A.calamus & $83.33 \pm 5.77$ & $83.33 \pm 5.77$ & $86.67 \pm 5.77$ & $86.67 \pm 5.77$ & $93.33 \pm 5.77$ & $96.67 \pm 5.77$ & 88.33 & $\mathrm{~V}$ \\
\hline $\begin{array}{l}\text { (Standard } \\
\text { check) }\end{array}$ & $(68.85)^{a}$ & $(66.14)^{a}$ & $(68.85)^{a}$ & $(68.85)^{a}$ & $(77.54)^{a}$ & $(83.52)^{a}$ & $(72.29)^{\mathrm{a}}$ & \\
\hline Mean & 61.39 & 66.39 & 71.11 & 71.67 & 74.44 & 77.78 & & \\
\hline SED & 2.85 & 2.67 & 3.29 & 3.09 & 4.25 & 3.73 & & \\
\hline
\end{tabular}

*Mean values of three replications are represented as mean \pm standard deviation; Figures in the parentheses are arcsine transformed values; In a column, the mean followed by the same letter are not significantly different from each other, DMRT ( $\leq \leq 0.05)$; SEd: Standard Error of the difference.

Abdelgaleil et al. (2016) reported that the Vitex agnus-castus essential oil caused $50 \%$ mortality at the concentration of $39.85 \mathrm{mg} \mathrm{L}^{-1}$ against S.oryzae. Sahaf et al. (2008) V.pseudo-negundo oil was toxic at the highest concentration of $925.9 \mu \mathrm{L} / \mathrm{L}$ air caused $100 \%$ mortality in 12 hours after treatment against S.oryzae. $370.4 \mu \mathrm{L} / \mathrm{L}$ air concentration caused $50 \%$ mortality at 12 hours of exposure and $90 \%$ mortality caused 24 hours of exposure, against S.oryzae. 


\section{Repellent activity}

The results on the repellency effect of ethyl acetate extracts against $S$. oryzae is presented in Table 2. The treated check A.calamus performed better in causing the highest mean repellent effect $88.33 \%$ (class V) of S. oryzae at $1 \%$ concentration. Among the test botanicals, M.spicata and O.sanctum showed maximum mean repellency $76.11 \%$ (class IV), followed by C.longa $75.56 \%$ mean repellency, but statistically on par with the $M$. spicata and O.sanctum followed by $V$. negundo leaf extract showed (72.78\%) mean repellency.

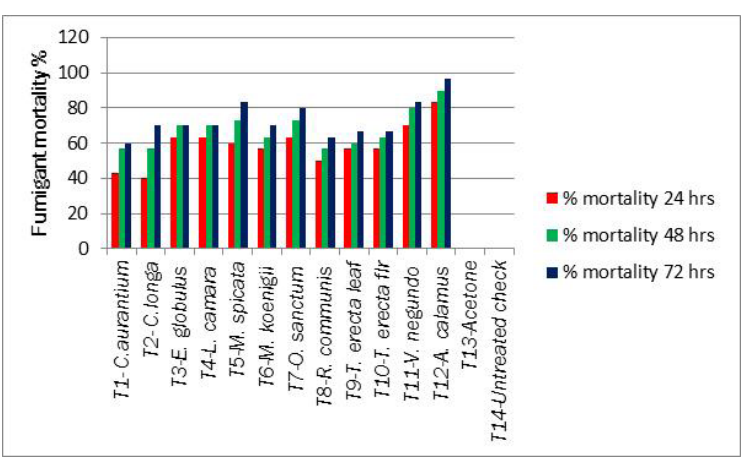

Figure 1. Fumigant toxicity of Ethyl Acetate extract of different plant materials against adults of S. oryzae.

The current results were corroborating with the findings of Khani et al. (2017), showed that M. piperita oil exhibited $95.0 \%$ repellency against S.oryzae. M.spicata oil showed $100 \%$ repellency at $0.025 \mu \mathrm{L} / \mathrm{mL}$ air concentration. Ouko et al. (2017) reported that the methanolic extracts of 0 . basilicum showed $72.5 \%$ repellent activity at $5^{\text {th }}$ hour of exposure at $25 \%$ concentration, a slightly higher repellent effect of $82.5 \%$ at $50 \%$ concentration after 3 hours of exposure, and greater repellence activities of $80 \%$ at $75 \%$ concentration and $87.5 \%$ at $100 \%$ concentration of extracts, against S. zeamais after 1hour of exposure. Soujanya et al. (2016) reported that the $V$.negundo extracts showed that $67.00 \%$ repellency after $6 \mathrm{hrs}$ of exposure.

\section{CONCLUSION}

Results suggested that the effectiveness of leaf extract of M. spicata against rice weevil( S.oryzae., a major storage insect pest of cereals like rice, maize, wheat, sorghum and barley. M.spicata ethyl acetate extract was found to possess both insecticidal and repellency effects against $S$. oryzae and it can reduce the dependency on chemical pesticides against S.oryzae in stored maize.

\section{REFERENCES}

Abbott, W. S. 1925. A method of computing the effectiveness of an insecticide. J. Econ. Entomol., 18(2): 265-267.
Abdelgaleil, S. A., Mohamed, M. I., Shawir, M. S. and H. K. Abou-Taleb. 2016. Chemical composition, insecticidal and biochemical effects of essential oils of different plant species from Northern Egypt on the rice weevil, S. oryzae L. J. Pest Sci., 89(1):219-229.

Ainane, A., Khammour, F., Mhammed, E. L., Talbi, M., Oussaid, A., Lemhidi, A., Oussaid, A. and T. Ainane. 2019. Evaluation of the toxicity of the essential oils of certain mints grown in the region of settat (morocco): Mentha piperita, Mentha pulegium and Mentha spicata against, Sitophilus granarius, $S$. oryzae and S. zeamais. JASAB., 1(1):1-1.

Batish, D. R., Singh, H. P., Kohli, R. K. and S. Kaur. 2008. Eucalyptus essential oil as a natural pesticide. For. Ecol. and manage., 256(12): 2166-2174.

Bhavya, M. L., Chandu, A. G. S. and S. S. Devi. 2018. Ocimum tenuiflorum oil, a potential insecticide against rice weevil with anti-acetylcholinesterase activity. Ind.Crops and Prod., 126: 434-439.

Demeter, S., Lebbe, O., Hecq, F., Nicolis, S. C., Kenne Kemene, T., Martin, H., Fauconnier, M. L. and T. Hance. 2021. Insecticidal activity of 25 essential oils on the stored product pest, Sitophilus granarius. Foods., 10(2): 200.

El-Salam, A. and M. E. Ahmed. 2010. Fumigant toxicity of seven essential oils against the cowpea weevil, Callosobruchus maculatus (F.) and the rice weevil, Sitophilus oryzae (L.). Egypt. Acad. J. Biol. Sci., 2(1): 1-6.

Gomez, K. A. and A.A. Gomez. 1984. Statistical procedures for agricultural research. John Wiley and Sons., 680.

Huang, Y., Lam, S. L. and S. H. Ho. 2000. Bioactivities of essential oil from Elletaria cardamomum (L.) Maton to S. zeamais Motschulsky and T. castaneum (Herbst). J. Stored Prod. Res., 36 (2): 107-117.

Jayakumar, M., Arivoli, S., Raveen, R. and S. Tennyson. 2017. Repellent activity and fumigant toxicity of a few plant oils against the adult rice weevil Sitophilus oryzae Linnaeus 1763 (Coleoptera: Curculionidae). J. Entomol. Zool.,5(2) : 324-335.

Khani, M., Marouf, A., Amini, S., Yazdani, D., Farashiani, M.E., Ahvazi, M., Khalighi-Sigaroodi, F. and A. Hosseini-Gharalari. 2017. Efficacy of three herbal essential oils against rice weevil, Sitophilus oryzae (Coleoptera: Curculionidae). J. Ess. Oil Bear. Plants,, 20(4): 937-950.

Ouko, R.O., Koech, S.C., Arika, W.M., Njagi, S.M., Oduor, R.O. and M.P. Ngugi. 2017. Bioefficacy of organic Extracts of Ocimum basilicum against Sitophilus zeamais. Entomol. Ornithol. Herpetol., 6(190):2161-0983.

Pandey, A. K., Singh, P., Palni, U. T. and N. N. Tripathi. 2011. Use of essential oils of aromatic plants for the management of pigeon pea infestation by pulse bruchids during storage. Int. J. Agric. Technol., 7: 1615-1624.

Saad, M. M., Abou-Taleb, H. K. and S. A. Abdelgaleil. 2018. Insecticidal activities of monoterpenes and phenylpropenes against Sitophilus oryzae and their inhibitory effects on acetylcholinesterase 
and adenosine triphosphatases. Appl. Entomol. Zool., 53(2): 173-181.

Sahaf, B.Z., Moharramipour, S. and M.H. Meshkatalsadat. 2008. Fumigant toxicity of essential oil from Vitex pseudo-negundo against Tribolium castaneum (Herbst) and Sitophilus oryzae (L.). J. Asia Pac. Entomol., 11(4): 175-179.

Shaaya, E., Kostjukovski, M., Eilberg, J. E., and C. Sukprakarn. 1997. Plant oils as fumigants and contact insecticides for the control of storedproduct insects. J. Stored Prod. Res., 33(1): 7-15.

Soujanya, P. L., Sekhar, J. C. and P. Kumar. 2016. Efficacy of plant extracts against rice weevil Sitophilus oryzae (L.) in stored maize. Indian J. Entomol., 78(4) : 342-345.

Talukder, F. A. and P. E. Howse. 1993. Deterrent and insecticidal effects of extracts of pithraj,
Aphanamixis polystachya (Meliaceae), against Tribolium castaneum in storage. J.Chem. Ecol., 19(11): 2463-2471.

Talukder, F. A. and P. E. Howse. 1994. Laboratory evaluation of toxic and repellent properties of the pithraj tree, Aphanamixis polystachya Wall \& Parker, against Sitophilus oryzae (L.). Int. J. Pest Manag., 40(3): 274-279.

Thomas, K. J., Selvanayagam, M., Raja, N. and S. Ignacimuthu. 2002. Plant products in controlling rice weevil Sitophilus oryzae. J.Sci.Ind Res., 61: 269-274.

Valsala, K. K. and M. Gokuldas. 2015. Repellent and oviposition deterrent effects of Clerodendrum infortunatum on the pulse beetle Callosobruchus chinensis L. (Coleoptera: Bruchidae). J. Entomol. Zool. Stud., 3(4): 250-253. 